\title{
Morality and Self-Control: \\ How They are Intertwined, and Where They Differ
}

\author{
Wilhelm Hofmann ${ }^{1}$, Peter Meindl ${ }^{2}$, Marlon Mooijman², and Jesse Graham ${ }^{4}$ \\ ${ }^{1}$ Social Cognition Center Cologne, University of Cologne, Germany \\ ${ }^{2}$ Department of Psychology, University of Pennsylvania, USA \\ ${ }^{3}$ Kellogg School of Management, Northwestern University, USA \\ ${ }^{4}$ Eccles School of Business, University of Utah, USA
}

In press, Current Directions in Psychological Science

\begin{abstract}
Despite sharing conceptual overlap, morality and self-control research have led largely separate lives. In this article, we highlight neglected connections between these major areas of psychology. To this end, we first note their conceptual similarities and differences. We then show how morality research, typically emphasizing aspects of moral cognition and emotion, may benefit from incorporating motivational concepts from self-control research. Similarly, selfcontrol research may benefit from a better understanding of the moral nature of many selfcontrol domains. We place special focus on various components of self-control and on the ways in which self-control goals may be moralized.
\end{abstract}

Keywords: morality, self-control, moralization, moral behavior 
What is the connection between our moral sense of right and wrong, and our capacity to resist temptations? In this article, we argue that many everyday challenges take place at the intersection of moral systems and the "master virtue" of self-control. Societies everywhere have created moral value systems that are passed on to (most) members of society through the process of socialization. These moral values and rules often motivate people to forego immediate, shortterm impulses and desires for the sake of others rather than personal benefits. Examples include restraining a sexual impulse to keep faithful to one's partner, resisting the urge to surf the web while at work, and suppressing aggressive impulses when being provoked. Presumably, the overarching societal outcome of such behavioral regulation is some sort of balance or tradeoff between individual interests and collective interests, such as public safety, order, and health (see Freud, 1930, for a classic treatment of this tradeoff). From this perspective, the individual capacity to regulate impulses and desires can be regarded as an important prerequisite for societal functioning.

The purpose of this article is to help build a stronger bridge between morality and selfcontrol research. With this goal in mind, we address three core questions regarding the connection between morality and self-control: First, what is the conceptual overlap between the two fields? Second, what can current self-control research teach us about when people succeed and when they do not succeed at translating moral standards into moral behavior? Third, what can research on morality tell us about when and why people moralize their self-control goals and what effect this moralization process has on self-control success?

\section{Conceptual Overlap and Differences}

Morality can be described as a culturally transmitted set of normative values and rules that enable people to live together in (more or less) harmony. Influential definitions of morality 
suggest that morality has two key functions (Durkheim, 1912/2008; Haidt, 2007): constraining action and providing identity. By helping to delineate and identify what is the morally "right" or "wrong” thing to do, morality constrains human action, primarily by reining in selfishness. Thus, moral systems “make cooperative social life possible” (Haidt \& Kesebir, 2010). Morality also serves to bind people who share moral values into a collective identity or ideological in-group (Graham \& Haidt, 2010; Haidt, 2012).

Self-control, on the other hand, can be defined as the "ability to override or change one's inner responses, as well as to interrupt behavioral tendencies (such as impulses) and refrain from acting on them” (Tangney, Baumeister, \& Boone, 2004, p. 274). According to related definitions, self-control becomes relevant whenever people have to deal with a motivational conflict between a short-term desire or goal and an opposing higher-order goal (e.g., Hofmann, Baumeister, Förster, \& Vohs, 2012; Kotabe \& Hofmann, 2015). Self-control thus enables the successful resolution of inner motivational conflicts in the service of such higher-order goals.

Viewed in concert, it is fair to say that morality and self-control interlock and form what we call moral self-control whenever people need to suppress a selfish impulse or desire in the service of a less selfish (e.g., cooperative, prosocial) moral value or goal. As such, moral selfcontrol can be contrasted with non-moral self-control, which is the suppression of a short-term self-interested desire in the service of a long-term self-interested goal. For example, resisting the desire to enjoy a steak to help promote a sustainable planet is an instance of moral self-control; resisting the very same desire in order to improve one's own health is an instance of non-moral self-control. This proposed definition of moral self-control also helps distinguish moral selfcontrol from other types of moral regulation or moral conflict resolution. For example, solving a moral dilemma between opposing moral values such as between loyalty and fairness —as in the 
case of whistleblowing (Waytz, Dungan, \& Young, 2013)—is an instance of moral regulation but not moral self-control (for a related view, see Monin, Pizarro, \& Beer, 2007).

In summary, not all moral failures are self-control failures (because not all morality requires self-control), and not all self-control failures are moral failures (because not all selfcontrol goals are moralized). Yet, self-control and morality overlap in important ways. This has implications for both research on morality and self-control, as detailed next.

\section{The Self-control $\rightarrow$ Morality Link}

Morality research often explores individual, situational, and cultural influences on moral judgment (i.e., what people consider the right or wrong thing to do in a given situation). But moral judgments, and their corresponding intentions, are only loosely related to actual moral behavior (e.g., Blasi, 1980). In order to understand why people’s moral ideals, values, judgments, and behavioral intentions do not always align with their actual behavior, it may be particularly useful to integrate self-control theories and frameworks. That is, why do some people sometimes have a hard time resisting a selfish impulse? From a broad self-control perspective, there are a number of distinct "problem spots” for translating moral standards into actual moral deeds, as summarized in Figure 1 (see Kotabe \& Hofmann, 2015, for an integrative model from which these components were derived): 


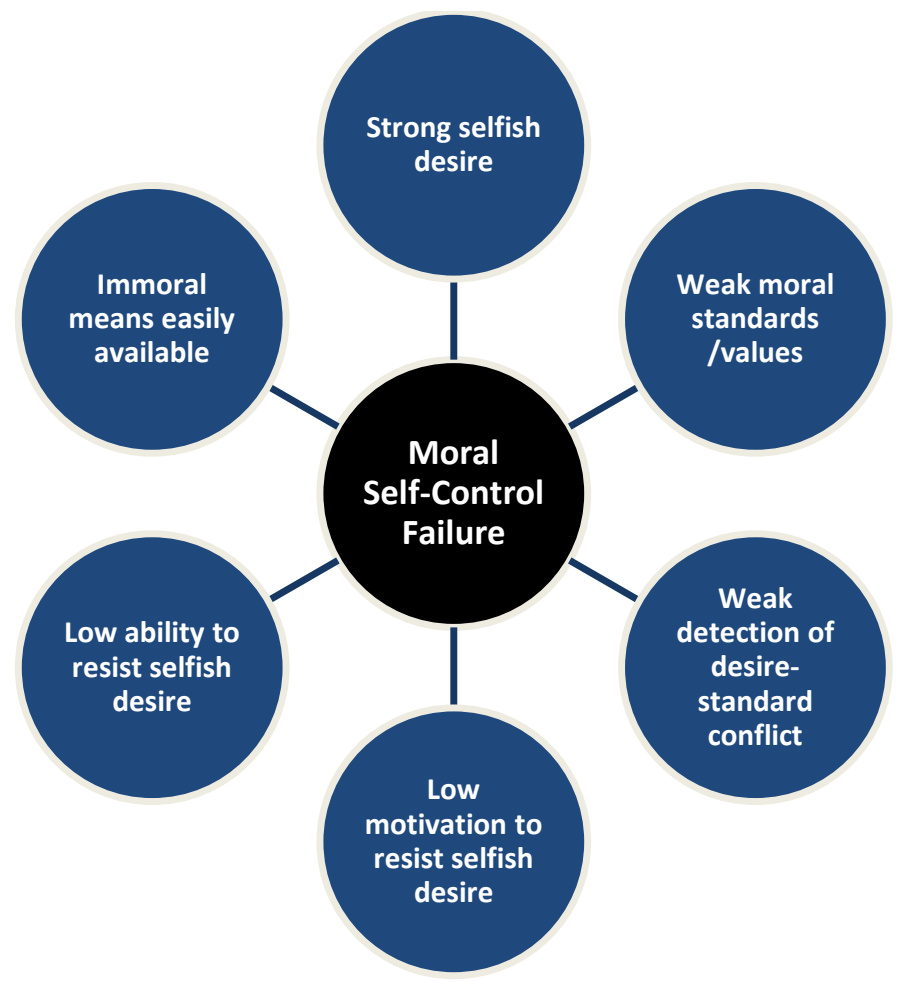

Figure 1. Key reasons for moral self-control failure (see text for details).

(1) Strong selfish desire: The motivational pull of the selfish desire may be very strong or “overpowering,” such as when large amounts of money are at stake (e.g., Schier, Ockenfels, \& Hofmann, 2016).

(2) Weak moral standards/values: The moral standards or values that motivate altruistic or cooperative behavior may only be weakly represented and endorsed, either temporarily (e.g., very abstract representation) or chronically (e.g., lack of internalization during socialization).

(3) Weak detection of desire-standard conflict: Most models of self-control assume that it's necessary to detect conflicts between desires and standards in order for self-control to be activated (e.g., Kotabe \& Hofmann, 2015; Sheldon \& Fishbach, 2015). Under certain conditions, people may fail to notice such a conflict between their selfish desire and an endorsed moral 
value. For instance, such self-monitoring can be hampered during acute alcohol intoxication (Hull, 1981).

(4) Low motivation to resist selfish desire: Despite endorsing a given moral value (and experiencing a conflict), at any given time people may not be motivated enough to resist a selfish desire. For instance, witnessing other people acting selfishly (e.g., working in a selfish corporate culture) may quickly kill the motivation to aspire to one's moral ideals (see also Cameron \& Shanker, in press, on compassion as a motivated choice). Also, people appear to trade off moral and immoral deeds over time, at least under some conditions. This might result in self-licensing or balancing (e.g., I was good before, so I deserve to be selfish now; Merritt, Effron, \& Monin, 2010; see also Hofmann et al., 2014), which conceptually links to motivational self-control failure (De Witt Huberts, Evers, \& De Ridder, 2014; Kotabe \& Hofmann, 2015).

(5) Low ability to resist selfish desire: The ability to resist temptation is related to executive functioning (EF), particularly inhibitory control and working memory capacity (for a review, see Hofmann, Schmeichel, \& Baddeley, 2012). EF can vary both due to chronic individual differences between people as well as temporary fluctuations due to situational factors like cognitive load (Ward \& Mann, 2000) or time of day (Kouchaki \& Smith, 2014). A considerable amount of research shows that when a person experiences a conflicting selfish urge, poor self-control makes it more difficult for the person to act morally (e.g., Gino, Schweitzer, Mead, \& Ariely, 2011; Knoch, Pascual-Leone, Meyer, Treyer, \& Fehr, 2006; Shalvi, Eldar, \& Bereby-Meyer, 2012). ${ }^{2}$

(6) Immoral means easily available: Even when a person has no (more) "inner constraints" to inhibit a selfish desire, external factors such as lack of time or money, as well as social (e.g., one’s partner) and physical (e.g., prison bars) barriers, can keep the person from 
enacting the desire. This factor is closely related to the emerging literature on choice architecture and nudging, which typically tries to identify and implement factors that render the immoral option less accessible or more difficult to carry out (Mazar \& Hawkins, 2015; Thaler \& Sunstein, 2008). An important avenue for future research is to better understand how such external nudges interact with internal factors such as the accessibility of moral values (e.g., Shu, Mazar, Gino, Ariely, \& Bazerman, 2012).

We believe that self-control and morality research will further converge in at least three ways. First, it is clear that self-control and moral behavior share dynamics over time, such that the parameters that give rise to both indulgent and immoral behavior may get readjusted as people gather feedback, and engage in attributions and processes of dissonance reduction afterwards. This may give rise to patterns of snowballing or slippery slope effects, including processes of moral disengagement (Bandura, Barbaranelli, Caprara, \& Pastorelli, 1996). Second, recent self-control research has made clear that the effortful inhibition of impulses is only one (late-stage) aspect of self-control and that proactive attempts to avoid temptation in the first place may be just as important (Fujita, 2011). This distinction has an intriguing parallel in the distinction between "will" (self-control) and "grace" (lack of temptation) in the moral domain (Greene \& Paxton, 2009), and raises the fascinating question of how these proactive forms of self-control can best be brought about. Third, the increased interest in how self-control may help initiate desired behaviors vs. inhibit undesired ones (de Ridder, de Boer, Lugtig, Bakker, \& van Hooft, 2011) resonates with the distinction between proscriptive (i.e., what should be done) vs. prescriptive (i.e., what should not be done) morality (Janoff-Bulman, Sheikh, \& Hepp, 2009). 


\section{The Morality $\rightarrow$ Self-Control Link}

But what of the converse relation: does morality contribute to self-control? As argued above, an important conceptual connection exists at the level of self-control goals. Moral values carry exceptional motivational power for self-restraint, so moralization has the potential to have a considerable influence on self-control behavior. The moralization of self-control is the process by which, over time, self-control preferences are converted into values (Rozin, 1999). This process can influence phenomena ranging from dietary restrictions (Rozin, Markwith, \& Stoess, 1997) to sexual abstinence (Haidt \& Hersh, 2001) and refraining from alcohol or drug use (Rozin \& Singh, 1999). But exactly what forms does this moralization take and is it effective for achieving self-control? ${ }^{3}$

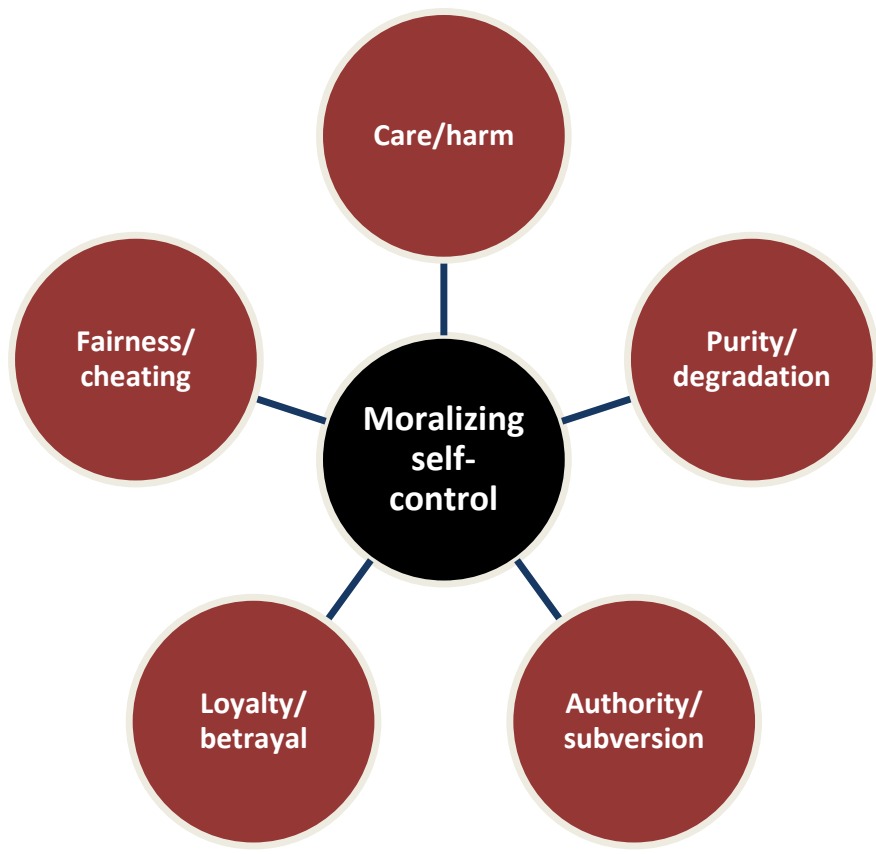

Figure 2. Key dimensions by which self-control goals can be moralized (see text for details). 
According to the well-established Moral Foundations Theory (Graham et al., 2013), morality is based on several core moral principles: Care/harm (i.e., "don’t harm other people”), Fairness/cheating (i.e., “don’t pursue your own advantage in disproportionate ways”), Loyalty/betrayal (i.e., “don’t betray your in-group”), Authority/subversion (i.e., “don’t disrespect rules, traditions, and authority figures”), and Purity/degradation (i.e., “don’t violate natural order or standards of decency”) (see Figure 2). ${ }^{4}$ Each of these may, in principle, serve as a moral reason for desire-regulation in the sense of a moral "ought” (i.e., proscriptive morality; JanoffBulman et al., 2009).

That said, some moral values appear to contribute more to the moralization process than others. Using Moral Foundations Theory as a framework, Mooijman, Meindl, Oyserman, Monterosso, Dehghani, Doris, and Graham (in press) showed in a series of studies involving large datasets and multiple conceptual replications that the group-focused, "binding" moral values of loyalty, authority, and purity (rather than "individualizing” values of care and fairness) play a particularly important role in the self-control moralization process. Specifically, these group-focused values were important predictors of why people perceived self-control as a moral issue. These moral values were also shown to mediate the effect of other predictors of moralization of self-control, including political conservatism, religiosity, and collectivism. Moreover, experimentally priming people to think of morality in a group- (vs. individual-) focused way increased moralization of self-control goals, whether those goals involved money, food, work, substances, relationships, or exercise. These findings highlight that converting selfcontrol into a moral value is a group-oriented process, thus uniting the constraining and binding functions of morality mentioned earlier. 
Not only do these findings show important conceptual connections between morality and self-control, they also open up more novel applied questions. First, they suggest that endorsing values such as loyalty, authority, and purity may make some individuals—such as religious or collectivist individuals—-better than others at achieving self-control success and avoiding selfcontrol failures (e.g., McCullough \& Willoughby, 2009). In addition, these results open up the question of how this may happen. Future research should test whether moralized self-control goals affect traditional components of the self-control process such as value strength or conflict detection (Kotabe \& Hofmann, 2015), or whether they perhaps enjoy more unique properties. Future work should also explore whether people extract greater "lessons” from self-control failures in moralized domains due to more intense positive/negative emotional feedback loops via feelings of pride or guilt, respectively (e.g., Baumeister, Vohs, DeWall, \& Zhang, 2007).

Second, although the findings from Mooijman et al (in press) suggest that the moralization of self-control occurs primarily through the group-focused binding foundations, the moral values of care and fairness may also contribute to the moralization process. For instance, paying more attention to buying fair-trade products or saving money to donate to a charity requires self-control and can be aimed at caring for others. Manipulations and interventions aimed at fostering the moralization of self-control goals and self-control success could "match" moral concerns with closely associated self-control behavior (e.g., care and fairness with fairtrade products or charity donations).

In addition, understanding how morality impacts self-control may also involve moving beyond interventions and experiments, tracking the moralization of different self-control behaviors over time using natural language processing techniques (e.g., analyzing the moralization of self-control behaviors in texts through Google Ngram Viewer; Mooijman et al., 
in press). For instance, this would allow researchers to test Rozin's notion that sex was the big moral topic of the $20^{\text {th }}$ century, but food will be the major moralized topic of the $21^{\text {st }}$ century (e.g., Rozin et al., 1997). It could also tell us when smoking cigarettes became moralized - and when smoking marijuana became less moralized.

\section{Conclusions}

How do we resist temptation, prioritizing our future well-being over our present pleasure? And how do we resist acting selfishly, prioritizing the needs of others over our own self-interest? These two questions highlight the links between understanding self-control and understanding morality. We hope we have shown that morality and self-control share considerable conceptual overlap with regard to the way people regulate behavior in line with higher-order values and standards. As the psychological study of both areas becomes increasingly collaborative and integrated, insights from each subfield can better enable research and interventions to increase human health and flourishing. 


\section{Notes}

${ }^{1}$ Address correspondence to Wilhelm Hofmann, Social Cognition Center Cologne, University of Cologne, Richard-Strauss Str. 2, 50931 Cologne, Germany.

${ }^{2}$ Note that this prediction is conditional on there being a selfish impulse (in conflict with a less selfish value) to begin with. We believe that the current debate surrounding the more general question of whether humans are "selfish" or "prosocial” by nature or default (Rand, Greene, \& Nowak, 2012) may not only be advanced through careful methodological considerations (Bouwmeester et al., 2017) but also by relaxing strong theoretical background assumptions (e.g., that the presence of selfish impulses and the strength of such impulses would not differ between people; that various decision contexts would trigger such impulses to the same extent etc.) in favor of a more nuanced, process-based perspective and measurement approach.

${ }^{3}$ Note that we do not take any normative position here. Some may argue, for instance, that moral concepts should be banned from the discourse on, for example, healthy and unhealthy food choices. To this we would reply that, since people do have moral thoughts and do use morally-relevant terms, self-control researchers should, instead, take the phenomenon of moralization seriously and scrutinize both its roots and its possible effects on the self-control process towards a better descriptive understanding of the phenomenon at hand.

${ }^{4}$ Another, separable core moral principle may be Honesty (i.e., “don’t lie or bend the truth”; Graham, Meindl, Koleva, Iyer, \& Johnson, 2015; Hofmann et al., 2014). 


\section{References}

Bandura, A., Barbaranelli, C., Caprara, G. V., \& Pastorelli, C. (1996). Mechanisms of moral disengagement in the exercise of moral agency. Journal of Personality and Social Psychology, 71, 364.

Baumeister, R. F., Vohs, K. D., DeWall, N., \& Zhang, L. (2007). How emotion shapes behavior: Feedback, anticipation, and reflection, rather than direct causation. Personality and Social Psychology Review, 11, 167-203.

Blasi, A. (1980). Bridging moral cognition and moral action: A critical revier of the literature. Psychological Bulletin, 88, 1-45.

Bouwmeester, S., Verkoeijen, P. P., Aczel, B., Barbosa, F., Bègue, L., Brañas-Garza, P., . . . Espín, A. M. (2017). Registered Replication Report: Rand, Greene, and Nowak (2012). Perspectives on Psychological Science, 12, 527-542.

Cameron, C. D., \& Shanker, K. (in press). Compassion is a motivated choice. In W. SinnottArmstrong (Ed.), Moral Psychology, Vol 5: Virtues and Vices: MIT Press.

de Ridder, D. T., de Boer, B. J., Lugtig, P., Bakker, A. B., \& van Hooft, E. A. (2011). Not doing bad things is not equivalent to doing the right thing: Distinguishing between inhibitory and initiatory self-control. Personality and Individual Differences, 50, 1006-1011.

De Witt Huberts, J. C., Evers, C., \& De Ridder, D. T. (2014). "Because I am worth it": a theoretical framework and empirical review of a justification-based account of selfregulation failure. Personality and Social Psychology Review, 18, 119-138.

Durkheim, E. (1912/2008). The elementary forms of the religious life. Oxford: Oxford University Press.

Freud, S. (1930). Civilization and its discontents. London: Hogarth. 
Fujita, K. (2011). On conceptualizing self-control as more than the effortful inhibition of impulses. Personality and Social Psychology Review, 15, 352-366.

Gino, F., Schweitzer, M. E., Mead, N. L., \& Ariely, D. (2011). Unable to resist temptation: How self-control depletion promotes unethical behavior. Organizational Behavior and Human Decision Processes, 115, 191-203.

Graham, J., \& Haidt, J. (2010). Beyond beliefs: religions bind individuals into moral communities. Personality and Social Psychology Review, 14, 140-150.

Graham, J., Haidt, J., Koleva, S., Motyl, M., Iyer, R., Wojcik, S. P., \& Ditto, P. H. (2013). Moral foundations theory: The pragmatic validity of moral pluralism. Advances in Experimental Social Psychology, 47, 55-130.

Graham, J., Meindl, P., Koleva, S., Iyer, R., \& Johnson, K. M. (2015). When values and behavior conflict: Moral pluralism and intrapersonal moral hypocrisy. Social and Personality Psychology Compass, 9, 158-170.

Greene, J. D., \& Paxton, J. M. (2009). Patterns of neural activity associated with honest and dishonest moral decisions. Proceedings of the National Academy of Sciences, 106, 12506-12511.

Haidt, J. (2007). The new synthesis in moral psychology. Science, 316, 998-1002.

Haidt, J. (2012). The righteous mind: Why good people are divided by politics and religion. New York: Pantheon.

Haidt, J., \& Hersh, M. A. (2001). Sexual morality: The cultures and emotions of conservatives and liberals. Journal of Applied Social Psychology, 31, 191.

Haidt, J., \& Kesebir, S. (2010). Morality. In F. S., D. Gilbert \& G. Lindzey (Eds.), Handbook of Social Psychology (Vol. 5th Edition, pp. 797-832). Hobeken, NJ: Wiley. 
Hofmann, W., Baumeister, R. F., Förster, G., \& Vohs, K. D. (2012). Everyday temptations: an experience sampling study of desire, conflict, and self-control. Journal of Personality and Social Psychology, 102, 1318-1335.

Hofmann, W., Schmeichel, B. J., \& Baddeley, A. D. (2012). Executive functions and selfregulation. Trends in Cognitive Sciences, 3, 174-180.

Hofmann, W., Wisneski, D. C., Brandt, M. J., \& Skitka, L. J. (2014). Morality in everyday life. Science, 345, 1340-1343.

Hull, J. G. (1981). A self-awareness model of the causes and effects of alcohol-consumption. Journal of Abnormal Psychology, 90, 586-600.

Janoff-Bulman, R., Sheikh, S., \& Hepp, S. (2009). Proscriptive versus prescriptive morality: two faces of moral regulation. Journal of Personality and Social Psychology, 96, 521-537.

Knoch, D., Pascual-Leone, A., Meyer, K., Treyer, V., \& Fehr, E. (2006). Diminishing reciprocal fairness by disrupting the right prefrontal cortex. Science, 314, 829-832.

Kotabe, H. P., \& Hofmann, W. (2015). On integrating the components of self-control. Perspectives on Psychological Science, 10, 618-638.

Kouchaki, M., \& Smith, I. H. (2014). The morning morality effect: The influence of time of day on unethical behavior. Psychological Science, 25, 95-102.

Mazar, N., \& Hawkins, S. A. (2015). Choice architecture in conflicts of interest: Defaults as physical and psychological barriers to (dis) honesty. Journal of Experimental Social Psychology, 59, 113-117.

McCullough, M. E., \& Willoughby, B. L. B. (2009). Religion, self-regulation, and self-control: Associations, explanations, and implications. Psychological Bulletin, 135, 69-93. 
Merritt, A. C., Effron, D. A., \& Monin, B. (2010). Moral self-licensing: When being good frees us to be bad. Social and Personality Psychology Compass, 4, 344-357.

Monin, B., Pizarro, D. A., \& Beer, J. S. (2007). Deciding versus reacting: Conceptions of moral judgment and the reason-affect debate. Review of General Psychology, 11, 99-111.

Mooijman, M., Meindl, P., Oyserman, D., Montereosso, J., Dehghani, M., Doris, J. M., \& Graham, J. (in press). Resisting temptation for the good of the group: Binding moral values and the moralization of self-control. . Journal of Personality and Social Psychology.

Rand, D. G., Greene, J. D., \& Nowak, M. A. (2012). Spontaneous giving and calculated greed. Nature, 489, 427-430.

Rozin, P. (1999). The process of moralization. Psychological Science, 10, 218-221.

Rozin, P., Markwith, M., \& Stoess, C. (1997). Moralization and becoming a vegetarian: The transformation of preferences into values and the recruitment of disgust. Psychological Science, 8, 67-73.

Rozin, P., \& Singh, L. (1999). The moralization of cigarette smoking in the United States. Journal of Consumer Psychology, 8, 321-337.

Schier, U. K., Ockenfels, A., \& Hofmann, W. (2016). Moral values and increasing stakes in a dictator game. Journal of Economic Psychology, 56, 107-115.

Shalvi, S., Eldar, O., \& Bereby-Meyer, Y. (2012). Honesty requires time (and lack of justifications). Psychological Science, 23, 1264-1270.

Sheldon, O. J., \& Fishbach, A. (2015). Anticipating and resisting the temptation to behave unethically. Personality and Social Psychology Bulletin, 41, 962-975. 
Shu, L. L., Mazar, N., Gino, F., Ariely, D., \& Bazerman, M. H. (2012). Signing at the beginning makes ethics salient and decreases dishonest self-reports in comparison to signing at the end. Proceedings of the National Academy of Sciences, 109, 15197-15200.

Tangney, J. P., Baumeister, R. F., \& Boone, A. L. (2004). High self-control predicts good adjustment, less pathology, better grades, and interpersonal success. Journal of Personality, 72, 271-324.

Thaler, R., \& Sunstein, C. (2008). Nudge: Improving decisions about health, wealth, and happiness. . New Haven, CT: Yale University Press.

Ward, A., \& Mann, T. (2000). Don't mind if I do: Disinhibited eating under cognitive load. Journal of Personality and Social Psychology, 78, 753-763.

Waytz, A., Dungan, J., \& Young, L. (2013). The whistleblower's dilemma and the fairnessloyalty tradeoff. Journal of Experimental Social Psychology, 49, 1027-1033. 


\section{Recommended Readings}

1. Rozin, P. (1999). The process of moralization. Psychological Science, 10, 218-221.

- A short and groundbreaking piece on the dynamics and effects of moralization over time.

2. Mooijman, M., Meindl, P., Oyserman, D., Montereosso, J., Dehghani, M., Doris, J. M., \& Graham, J. (in press). Resisting temptation for the good of the group: Binding moral values and the moralization of self-control. Journal of Personality and Social Psychology.

- A Multi-method investigation taking a pluralist approach to both morality and self-control, detailing which kinds of moral concerns (e.g., fairness, purity) impact moralization of different self-control domains (e.g., exercise, money).

3. Kotabe, H. P., \& Hofmann, W. (2015). On integrating the components of self-control. Perspectives on Psychological Science, 10, 618-638.

- An integrative overview of major conceptual hubs in self-control research and how these may interact together.

4. Monin, B., Pizarro, D. A., \& Beer, J. S. (2007). Deciding versus reacting: Conceptions of moral judgment and the reason-affect debate. Review of General Psychology, 11, 99.

- A very readable conceptual overview distinguishing different prototypical situations in moral judgment, including moral dilemmas, moral reactions, and moral temptation. 